\title{
A CONSTRUÇÃO DE UM CURRÍCULO TRANSDISCIPLINAR PARA A EDUCAÇÃO SUPERIOR
}

\author{
Maria de Fátima Viegas Josgrilbert \\ Faculdades Magsul (Brasil) \\ fatimagsul@terra.com.br · https://orcid.org/0000-0003-4983-8624 \\ João Henrique Suanno \\ Universidade Estadual de Goiás - UEG (Brasil) \\ suanno@uol.com.br·https://orcid.org/0000-0003-0624-5378
}

\begin{abstract}
Resumo. A finalidade deste artigo é narrar uma iniciativa didático-pedagógica de reconstrução de um design curricular dos cursos superiores de uma faculdade sob o enfoque transdisciplinar. Para isso, perguntou-se o seguinte: primeiro modifica-se o projeto ou a atitude dos professores? Para responder essa questão e acompanhar a ação pedagógica, foi desenvolvida uma pesquisa qualitativa com o apoio de um grupo focal. Outras questões também precisaram ser repensadas, como: a importância do curso para a região, a clientela, a equipe de professores, o espaço físico, o foco do curso, tudo isso tendo como base a missão da instituição. Observou-se que um currículo inter/transdisciplinar favorece a articulação entre os conteúdos científicos e os conteúdos da vida, resultando em um compromisso social da instituição na formação de um egresso que busque a concretização da cidadania, bem como a construção de uma sociedade mais justa. O exercício de repensar o curso também foi modificando o pensar dos docentes.
\end{abstract}

Palavras-chave: Transdisciplinaridade, interdisciplinaridade, currículo.

\section{CONSTRUCTION A TRANSDISCIPLINARY CURRICULUM TO HIGHER EDUCATION}

\begin{abstract}
The objective of this article is to narrate a pedagogical, didactical undertaking in reconstructing a curriculum structure in the context of undergraduate school, and under a transdisciplinary perspective. What would come first: changing the project or changing the professor's attitude? In order to answer to this question in the pedagogical process we developed a focal group research project. Other questions shall be considered too, such us the importance for the region and the customer related to a given academic degree; the teachers, the physical space, the focus of the discipline, in the horizon of the mission of the institution. An inter/transdisciplinarity curriculum favors the connection between scientific and daily life elements, promoting an institutional social engagement through the formation of students that seek to promote citizenship in a more just society. The task of rethinking the disciplines slowly transformed the professor's minds.
\end{abstract}

Keywords: Transdisciplinarity, interdisciplinarity, curriculum.

\section{LA CONSTRUCIÓN DE UN CURRÍCULO TRANSDISCIPLINAR PARA LA EDUCACIÓN SUPERIOR}

Resumen. La finalidad de este artículo es narrar una iniciativa didáctico-pedagógica de construcción de un diseño curricular de las carreras en una universidad, bajo el enfoque transdisciplinar. ¿Qué hacer primero: modificar el proyecto o la actitud de los profesores? Para contestar a esta pregunta en medio del proceso 
pedagógico, fue llevada a cabo una investigación cualitativa con apoyo de un grupo focal. Otras preguntas también han sido tomadas en consideración, sobre la importancia de las carreras universitarias para la región, la clientela, el equipo de profesores, el espacio físico, el enfoque de las asignaturas, todo esto teniendo como base la misión de la institución. Se ha observado que un currículo inter/transdisciplinar favorece la articulación entre los contenidos científicos y los contenidos de la vida humana, resultando un compromiso social de la institución con la formación de un egresado que busque la concretización de la ciudadanía, así como la construcción de una sociedad, mas justa. El ejercicio de repensar las carreras, cursos y disciplinas también fue modificando el pensamiento de los docentes.

Palabras clave: Transdisciplinariedad, interdisciplinariedad, currículo.

\section{Introdução}

Conectados ao pensamento de Morin (2013, p. 39, 40) de que "tudo sempre começa com uma iniciativa, uma inovação, uma nova mensagem de caráter desviante, marginal, com frequência invisível aos contemporâneos" e com o objetivo de narrar uma iniciativa didático-pedagógica para reconstruir os projetos pedagógicos de cursos superiores das Faculdades Magsul, de Ponta Porã, Mato Grosso do Sul, Brasil, sob o enfoque transdisciplinar, descreveremos os caminhos percorridos $\mathrm{e}$ as ações desenvolvidas nesse processo.

Essa reconstrução refere-se a um trabalho pedagógico de planejamento curricular, fundamentado nos estudos de pós-doutoramento da diretora da instituição realizados na Universidade Estadual de Goiás (UEG). A parceria entre as instituições se constituiu como fundamental para a efetivação da investigação, uma vez que a UEG possui um grupo de pesquisa na área da transdisciplinaridade.

O projeto pedagógico de um curso é o que define seu currículo e, consequentemente, traça as ações pedagógicas para que os objetivos educacionais sejam alcançados. Antes de começar sua construção, é necessário pensar: o Ensino Superior que temos é o que queremos? Ele está de acordo com as legislações que o direcionam? O que é possível transformar para atender aos anseios e às necessidades dos acadêmicos, da região e da sociedade do seu tempo? Essas reflexões estão focadas no que acontece no mundo, na sociedade e no âmbito da faculdade? Elas contribuem para a compreenção das influências do aprender sobre o saber, sobre o fazer e suas consequências para a vida humana.

Tais questionamentos nos levam a refletir de maneira mais ampla sobre a realidade educacional e sobre a forma como ela se apresenta, o que pode ser "um grande desafio para a grande maioria dos educadores acostumada a trabalhar com certezas e verdades, com estabilidade e previsibilidade, pensando que a linearidade é regra e não a exceção" (Moraes, 2010, p. 22).

Para pensar em um novo currículo, é indispensável superar a perspectiva das certezas e verdades e buscar soluções para os grandes problemas de natureza complexa. Em relação a isso, Morin (2013) nos alerta para a necessidade de reformarmos o pensamento para conseguirmos as mudanças desejadas: "Apenas as mentes reformadas poderiam reformar o sistema educacional, mas apenas um sistema educacional reformado poderia formar espíritos reformados" (p. 201). Esse paradoxo conduziu o nosso trabalho. 
O primeiro questionamento - $\mathrm{O}$ ensino superior que temos é o que queremos? leva-nos a refletir sobre a procura pela Educação Superior, que vem crescendo em relação ao quantitativo da oferta de vagas.

O total de alunos matriculados na educação superior brasileira ultrapassou a marca de 7 milhões em 2012. É o que apontam os dados do Censo da Educação Superior divulgados pelo Ministério da Educação [...]. Esse número representa aumento de 4,4\% no período 2011-2012. Enquanto o número de matrículas nas instituições públicas cresceu 7\%, o aumento na rede particular, responsável por $73 \%$ do total, foi de $3,5 \%$ (Instituto Nacional de Estudos e Pesquisas, 2013).

Apesar das mudanças no quantitativo de matrículas na Educação Superior, mudanças qualitativas são necessárias, pois os números muitas vezes escondem os insucessos de uma educação pautada pela especialização e pela fragmentação do saber. Teóricos apontam que uma educação de qualidade precisa estar focada no indivíduo e na vida, na realização individual e grupal.

Para que essas mudanças sejam eficientes, é necessário refletir sobre o momento em que vivemos e sobre a evolução da sociedade atual, para que possamos definir os sentidos da educação de nosso tempo, o papel dos sujeitos e os valores éticos, morais e culturais que precisam ser preservados. A partir dessas reflexões, podemos afirmar que vivemos momentos de grandes progressos nas diferentes áreas do conhecimento, mas também de instabilidades, incertezas, desconstruções, fragmentações, troca de valores, desvalorização do ser humano, violência, entre tantos problemas civilizatórios que surgem com a globalização e a pós-modernidade, abalando os indivíduos, as famílias e as demais estruturas sociais. Dentro desse panorama, evidenciamos a importância de uma educação de qualidade, que atenda às necessidades do século XXI, tendo como foco a eficiência do processo de ensino e aprendizagem.

Quanto à segunda questão proposta - O currículo está de acordo com as legislações que o direcionam? -, os cursos de graduação são avaliados, periodicamente, pelo Ministério da Educação (MEC) e precisam estar em consonância com a legislação educacional para terem autorização de funcionamento. Portanto, para se construir qualquer projeto de curso para a Educação Superior, é evidente que a legislação precisa ser atendida. Entretanto, no Art. 207 da Constituição Brasileira, encontramos: "As universidades gozam de autonomia didático-científica, administrativa e de gestão financeira e patrimonial, e obedecerão ao princípio de indissociabilidade entre ensino, pesquisa e extensão". A partir dessa afirmativa, podemos questionar: se existe autonomia didático-científica, o projeto pedagógico pode ser construído de acordo com os ideais da instituição? A resposta é não, percebemos que essa autonomia é relativa, uma vez que as Diretrizes Curriculares Nacionais (DCNs) possuem caráter obrigatório.

Ao consultar as Diretrizes Curriculares Nacionais para os cursos de graduação em Direito, podemos observar que esse documento questiona, no Art. $1^{\circ}$, inciso IV, como serão as formas de realização da interdisciplinaridade. Além disso, ele apresenta no Art. $3^{\circ}$ o perfil do graduando, no Art. $4^{\circ}$ as competências e habilidades que devem ser construídas e no Art. $5^{\circ}$ as disciplinas essenciais. Então, voltamos a questionar: existe autonomia?

Portanto, as instituições podem construir seus projetos pedagógicos inovadores desde que estes contenham os elementos estruturais elencados no Art. $1^{\circ}$ das DCNs. Assim, a construção dos projetos pedagógicos fica restrita a uma autonomia parcial de escolha de objetivos, de perfil profissional, de metodologia. Logo, a faculdade goza de "autonomia" desde que cumpra a legislação educacional vigente. Entretanto, mesmo com 
as imposições legais, a construção de um projeto pode ser criativa e levar a um currículo mais atualizado, coerente com a realidade e seu tempo, promovendo uma formação integral.

Assim, chega-se ao terceiro questionamento - O que é possível transformar para a melhoria do Ensino Superior, dentro dessa autonomia relativa? -, que aponta para a responsabilidade das instituições de ensino na construção de seus currículos. Essa autonomia na construção do currículo, pelas instituições de ensino, é uma das condições fundamentais para que se realize uma reforma educacional que melhore a qualidade da educação. Com esse compromisso de busca pela qualidade, acreditamos que a primeira ação pedagógica deve ser a elaboração de um projeto de curso, com características próprias, adequado aos anseios dos alunos e da realidade da região onde a faculdade está inserida. Essa é, portanto, a base que pode estruturar a melhoria do processo de ensino e aprendizagem e que pode atender às expectativas da sociedade, desde que as mentes dos responsáveis pela reforma estejam reformadas ou se reformando.

Assim sendo, acreditamos em um projeto flexível, sempre repensado, atualizado e adequado à realidade, que conduza à formação de um profissional com capacidade de resolver problemas e de adaptar-se às mudanças e aos novos processos tecnológicos, utilizando tanto a criatividade quanto o raciocínio.

A reconstrução dos projetos dos cursos das Faculdades Magsul foi norteada pelas palavras e expressões oriundas dos questionamentos - qualidade de educação, reforma, legislação, novo currículo - e pelo sonho de construir um curso superior cada vez melhor, com um olhar voltado para a vida.

A percepção sobre a importância da capacitação continuada para a mudança de atitude docente foi confirmada com a sugestão do professor, mas observávamos que nem todos estavam envolvidos com as questões metodológicas e ainda acreditavam que o conteúdo de suas disciplinas tinha um fim em si mesmo. Então, mais perguntas surgiram nesse processo: como melhorar esse cenário? Como reformar um curso propondo uma metodologia transdisciplinar? Como preparar os professores para que ocorra uma real mudança de atitude docente?

Os avanços precisavam acontecer, tanto na reestruturação do projeto do curso quanto na preparação dos docentes, uma vez que as reformas propostas até então não apontavam para uma equipe totalmente reformada na questão da atitude. Esse movimento pedagógico transformou-se em uma pesquisa com base nos questionamentos mencionados.

\section{Método}

Inicialmente, optamos por realizar um estudo de caso, conforme a proposta de Lüdke e André (1986), tendo como base da pesquisa a observação do comportamento dos professores que participavam dos encontros de capacitação continuada e suas opiniões sobre uma nova proposta curricular. Nesse caso, teríamos que sugerir uma proposta e esperar as mudanças, pois a "observação, depende da espera que as coisas aconteçam" (Gatti, 2012, p. 9).

Buscando um modelo de pesquisa com base em uma abordagem qualitativa, percebemos que o tipo grupo focal (GF) é um modelo que vem sendo utilizado e poderia ser útil dentro da proposta vislumbrada. "Powell e Single definem grupo focal como um 
conjunto de pessoas selecionadas e reunidas por pesquisadores para discutir e comentar um tema, que é objeto de pesquisa, a partir de uma experiência pessoal" (Gatti, 2012, p. 7).

Nosso objeto de pesquisa era claro e havia sido inspirado em um paradoxo proposto por Morin, que nos alerta: "não se pode reformar a instituição sem antes reformar as mentes, mas não se pode reformar as mentes sem antes reformar as instituições" (2013, p. 191). Desejávamos reformar o currículo do Curso de Direito das Faculdades Integradas de Ponta Porã/MS reformando as atitudes de seus professores, compreendendo currículo "como as experiências escolares que se desdobram em torno do conhecimento, em meio a relações sociais, e que contribuem para a construção das identidades de nossos/as estudantes" (Moreria e Candau, 2007, p. 18).

Com a equipe de professores definida, começamos três trabalhos paralelos: a capacitação dos professores nas questões relativas à Didática e às Metodologias de Ensino; o desenvolvimento de uma pesquisa do tipo grupo focal centrada nas reuniões de professores; e um estudo com o NDE para definir a construção do novo projeto. Esse projeto deveria atender à legislação de ensino, às necessidades regionais, à educação inclusiva e à missão da instituição. Partimos sempre dos projetos que já existiam, mas que precisavam de atualização.

Portanto, o primeiro passo desse trabalho foi um diagnóstico das propostas existentes, surgindo daí questões que precisaram ser repensadas, como: a importância do curso para o desenvolvimento da região, a clientela, a equipe de professores, o espaço físico, o foco do curso, os materiais necessários, tendo como base a missão da instituição, que é:

Atuar na produção e na disseminação dos saberes e práticas, de forma filosófica, científica, cultural, técnica e profissional, contribuindo assim para o desenvolvimento sustentável da região e, consequentemente, da qualidade de vida, visando à promoção do desenvolvimento da região Cone-Sul do Estado de Mato Grosso do Sul, oferecendo um ensino superior consciente e eficaz para que seus discentes possam concretizar seus projetos de vida (Faculdades Magsul, 2012, p. 6, grifo nosso).

Não se pretende apresentar um guia de elaboração de um projeto pedagógico para um curso superior, uma vez que cada instituição ou cada curso possui suas especificidades. Pretende-se relatar as reflexões e as experiências vividas pela equipe docente e pelo Núcleo Docente Estruturante (NDE), grupo responsável pela construção dos projetos dos cursos das Faculdades Magsul.

Ao serem observadas as expressões "desenvolvimento sustentável", "qualidade" e "projetos de vida", apontadas anteriormente, os debates sobre a base metodológica do curso foram se encaminhando para uma abordagem transdisciplinar. Uma vez que, para alcançar esses objetivos, os cursos precisam ser organizados para que se construa uma atitude consciente de se ver o mundo e de se conceber o conhecimento, priorizando a vida e o meio ambiente. Essa atitude será, consequentente, apresentada na matriz curricular, com as disciplinas organizadas para promoverem um trabalho interdisciplinar, mas com objetivos que as transcendam. De acordo com Nicolescu (2000, p. 15), a transdisciplinaridade tem como objetivo "a compreensão do mundo presente, para o qual um dos imperativos é a unidade do conhecimento."

Para tal reconstrução, também se perguntou, afinal, qual seria a proposta metodológica mais adequada para o curso? Diante das propostas de interdisciplinaridade, segundo Fazenda (2008), e de transdisciplinaridade, segundo Morin (2000), Nicolescu 
(2000), Torre, Pujol e Moraes (2008) e outros - e entendendo que as duas teorias se completam -, os estudos foram fundamentados nelas.

Conforme Moraes (2008, p. 63): “ambos os conceitos estão associados a algo muito mais amplo e profundo relacionado com a compreensão do funcionamento do real, além do processo de construção do conhecimento." A autora complementa que: "Com a interdisciplinaridade integramos, e com a transdisciplinaridade transcendemos a subjetividade objetiva do sujeito que conhece” (p. 65), portanto são conceitos harmônicos que se completam. Considera-se aqui a interdisciplinaridade não como um saber único e organizado, nem apenas uma reunião ou abandono de disciplinas, e sim como uma nova atitude, uma forma de ver o mundo e de conceber o conhecimento, que as disciplinas, isoladamente, não conseguem atingir e que surge da comunicação entre os saberes (Josgrilbert, 2004).

Para verificar as possibilidades de construção de um novo currículo e refletindo sobre o paradoxo proposto por Morin (2013), ao dizer que apenas as mentes reformadas poderiam reformar o ensino, mas que só a reforma de ensino poderia reformar as mentes, resolvemos criar um grupo focal de pesquisa para verificar como poderíamos preparar nossos docentes para a reforma almejada. Esta investigação foi feita no Curso de Direito, no primeiro semestre de 2015 e definida pelos seguintes passos: estudo documental das DCNs e do Projeto de Curso existente; revisão bibliográfica sobre a inter e a transdisciplinaridade; estudo minucioso da matriz e das ementas do curso pela equipe de professores, verificando as possibilidades de conexão entre os saberes; acompanhamento, observação e análise das capacitações continuadas e das reuniões de professores e de acadêmicos do último ano. Isso foi feito para a construção de uma nova matriz curricular, com base na transdisciplinaridade, representada em forma de design. Com a investigação, buscávamos elementos que justificassem como poderia se dar a reforma do pensamento dos docentes do curso e a reforma do próprio curso.

O grupo focal (GF) foi escolhido como modelo de pesquisa pois "permite compreender processos de construção da realidade por determinados grupos sociais, compreender práticas cotidianas, ações e reações a fatos e eventos, comportamentos e atitudes... por pessoas que partilham alguns traços em comum" (Gatti, 2012, p. 11). Além disso, ele foi priorizado, dentro das abordagens qualitativas, pelos seguintes motivos: por ser uma técnica de pesquisa que contribui com novas ideias oriundas de diferentes vertentes que vivenciam o processo, neste caso, os docentes e discentes envolvidos; por poder oportunizar a interpretação de valores, conceitos, conflitos, pontos de vista; por possibilitar o entendimento do tema no cotidiano; por ser uma técnica rica para captar conhecimentos e informações que podem ser úteis para a complementação do trabalho e dos estudos subsequentes.

Reunimos dois grupos focais que poderiam contribuir de forma relevante para a construção de um novo modelo curricular: o grupo de docentes e o grupo de acadêmicos concluintes (subdivido em 4 grupos). Esses grupos tinham características comuns: haviam vivenciado o curso sob duas óticas diferentes e poderiam trazer elementos com base nas suas vivências cotidianas. Eles estavam integrados ao objeto da pesquisa e, portanto, foram utilizados para a coleta de dados. O grupo de discentes foi menos utilizado, porém suas contribuições não foram desconsideradas. $\mathrm{O}$ grupo de docentes foi o foco principal dos estudos, pois tinha mais a contribuir. Ambos, porém, trouxeram ideias relevantes e originais. Os docentes foram escolhidos como grupo principal da pesquisa por causa da delimitação do próprio objeto e porque acreditávamos que, participando como um grupo efetivo da pesquisa, iríamos, paralelamente, modificando as 
atitudes frente ao modelo de currículo que tínhamos e o que queríamos. Foram escolhidas, para coordenar os grupos, duas professoras, uma como moderadora e responsável pela condução dos trabalhos e outra como relatora, com o compromisso de gravar ou anotar o desenvolvimento dos trabalhos, ambas podendo alternar suas funções.

Os dados escolhidos para análise foram coletados nas reuniões de docentes e discentes, no período de abril a junho de 2015, por meio de gravações, fotos e anotações escritas, acrescidas das contribuições das reuniões com o NDE. Nesse período, só coletamos dados referentes ao primeiro ano do curso. Caminhamos devagar porque precisávamos que os professores tivessem tempo de conhecer a teoria transdisciplinar, por meio das leituras sugeridas e das capacitações.

O GF de docentes foi observado durante o trabalho de análise feito das ementas de todas as disciplinas do curso e de reconstrução da nova matriz curricular. Os professores, ao conhecer o conteúdo de cada disciplina, também refletiram em conjunto sobre suas relações e pontos de ligação.

Ficou estabelecido que, para não atrapalhar o estudo minucioso feito pelo GF, não agiríamos com pressa. Os professores perceberam as dificuldades que se enfrentam para construir um bom projeto frente: às legislações que precisam ser cumpridas, como as exigências das DCNs, que determinam os eixos das disciplinas, as competências, a carga horária; ao Exame Nacional de Desempenho de Estudantes (ENADE); e às avaliações do MEC. O GF concluiu que traçar uma teia transdisciplinar para o Ensino Superior é muito mais complicado do que para a Educação Básica, pois não se pode fugir de algumas prerrogativas legais que priorizam os conteúdos disciplinares, apresentados de forma fragmentada. Em função das ideias que surgiam e dos objetivos que iam sendo alcançados, íamos reconstruindo, com o NDE, o design do curso. Logo, os professores iam contribuindo com o novo currículo.

Enquanto os professores discutiam as ementas das disciplinas e buscavam seus pontos de ligação para a construção de um currículo transdisciplinar, conversamos, também, com os quatro grupos de alunos, reparando que suas falas se repetiam. As sugestões dos alunos, em relação às disciplinas, coincidiram com a proposta dos professores. Foi possível perceber que valorizavam o curso, apresentando mais pontos positivos do que negativos. Entretanto, afirmaram que, apesar de verificarem um esforço dos professores, a disciplina Projeto de Pesquisa Interdisciplinar ainda não conseguia integrar devidamente todas as disciplinas; falaram também que, no início do curso, não entendiam a função dessa disciplina e, por isso, não havia um bom rendimento. No final do curso, já entendiam sua finalidade e julgavam-na importante, mas acreditavam que algo precisava mudar, sem saber o quê. Os professores concordaram com as sugestões dos acadêmicos.

O desenvolvimento do trabalho de pesquisa, caminhando junto com a capacitação continuada, foi dando condições para se compreender a importância de um currículo transdisciplinar que, além de integrar as disciplinas para a construção do conhecimento, proporciona uma dimensão maior de articulação entre os conteúdos científicos e os conteúdos da vida humana. Assim, o acadêmico tem a possibilidade de construir um compromisso individual e social, ou seja, que busca uma efetiva e concreta cidadania, bem como a construção de uma sociedade mais justa, humana, solidária e igualitária.

Construindo o novo currículo, como resultado da pesquisa desenvolvida, nossa visão e concepção sobre o curso ia se modificando. $\mathrm{O}$ exercício de repensar o curso também foi modificando o pensar dos docentes. O grupo de professores compreendeu e visualizou o todo (o currículo) e as partes (as disciplinas) percebendo seus encaixes e 
múltiplas relações. Estávamos modificando o currículo do curso e, junto, preparando os professores.

\section{Construção do projeto de curso}

Com os estudos documentais e com a análise das reuniões dos grupos focais, começamos a esboçar a nova proposta curricular. Partimos da missão institucional para delinear o perfil do egresso que se pretendia e o objetivo geral do curso: três metas ligadas entre si, demonstrando que a missão, os objetivos do curso e o perfil almejado se entrelaçam em um movimento que permeia todo o curso na construção de um profissional competente que atenda às necessidades do seu meio, do seu tempo e da sua realização pessoal.

Com a definição dessa tríade, partimos para dois eixos interrelacionados: os objetivos específicos contidos nas disciplinas formadoras da matriz curricular, e traçados pelos professores, e as competências/habilidades a serem construídas pelos alunos. Para a organização de um curso, precisamos ter claro o conjunto de habilidades e competências necessárias à profissão, para utilizá-las como norteadoras da proposta pedagógica, da organização da instituição e de sua gestão. Para tanto, os cursos superiores devem definir com precisão, em seus projetos, as competências e habilidades a serem desenvolvidas, tendo como parâmetro as necessidades reais da comunidade e da profissão e a legislação vigente. É importante que isso seja apresentado aos alunos, para que saibam o que se espera deles ao final do curso e, ao mesmo tempo, para que verifiquem se essas ideias são compatíveis com seus projetos de vida.

A inter e a transdisciplinaridade foram consideradas eixos de sustentação do caminhar metodológico, tendo-se como meta as habilidades e as competências que se pretendem construir, acreditando-se que aquele que aprende deve construir seu pensamento com base em três modalidades temporais: passado (conhecimento acumulado pela humanidade), presente (reflexão sobre a realidade) e futuro (possibilidades transformadoras). A noção de temporalidade é importante para que se perceba a evolução do pensamento e do conhecimento.

A partir dos estudos desenvolvidos na instituição, percebemos que o conhecimento deveria ser construído pelos acadêmicos em um caminhar espiralado crescente, conforme apresentamos no design adiante, que evolui adotando um trajeto que permite a construção do conhecimento obedecendo à seguinte sequência: 1) conhecer o assunto que se vai aprender para depois compreendê-lo; 2) compreendendo é que se torna possível refletir sobre o tema (análise e síntese); 3) a partir da compreensão e da reflexão, torna-se possível avaliá-lo (fazendo um juízo de valor sobre a sua importância); 4) finalmente, pode-se aplicá-lo, transformando/melhorando uma nova situação e a própria vida de forma consciente e segura.

\section{Estrutura organizacional curricular e metodologia}

Para continuar o trabalho de organização do curso, pensamos na escolha das disciplinas, em seus objetivos, seus ementários e nas indicações bibliográficas, sem 
perder o foco da missão da instituição de cunho transdisciplinar, do objetivo geral e do perfil profissional pretendido, respeitando-se as características regionais.

O ordenamento e a escolha das disciplinas formadoras da matriz curricular são os primeiros passos para a construção do currículo, lembrando-se que as DCNs trazem um elenco das essenciais; entretanto, a instituição deve pensar como vão ser estabelecidas as relações entre elas. São essas relações que vão determinar as características do currículo. A transdisciplinaridade não abandona o ensino disciplinar, mas "busca religar saberes e, nesse processo, valoriza o saber disciplinar e especializado, como parte, no entanto o transcende por investir na formação humana" (Suanno, 2014, p. 14).

Em um currículo disciplinar, as disciplinas são fechadas em si mesmas e não há preocupação de relacioná-las com as outras, somente com as que são consideradas "prérequisitos". Em um currículo que se diz inter ou transdisciplinar, é preciso que se pense em múltiplas relações horizontais e verticais, com um olhar focado não nas disciplinas, mas na formação do indivíduo, com saberes tecidos em conjunto.

Para a organização do currículo do curso de Direito das Faculdades Magsul, pensamos em múltiplas relações, tais como as temporais, relacionadas a passado, presente e futuro. Assim, consideramos como passado as disciplinas que contêm o conhecimento acumulado pela humanidade; como presente, as que levam à reflexão sobre esses conhecimentos e suas influências na profissão e na sociedade no momento atual; e como futuro, as inúmeras possibilidades de transformações com base nesses conhecimentos, tanto no âmbito individual como no profissional.

Outra relação considerada tem como base a classificação das disciplinas. No caso do curso de Direito, as DCNs dividem as disciplinas em três eixos: eixo de formação fundamental, eixo de formação profissional e eixo de formação prática. Na matriz curricular, usamos cores para representar tanto essa classificação como cada semestre. Essas relações podem ser observadas no design curricular criado e apresentado na Figura 1. 


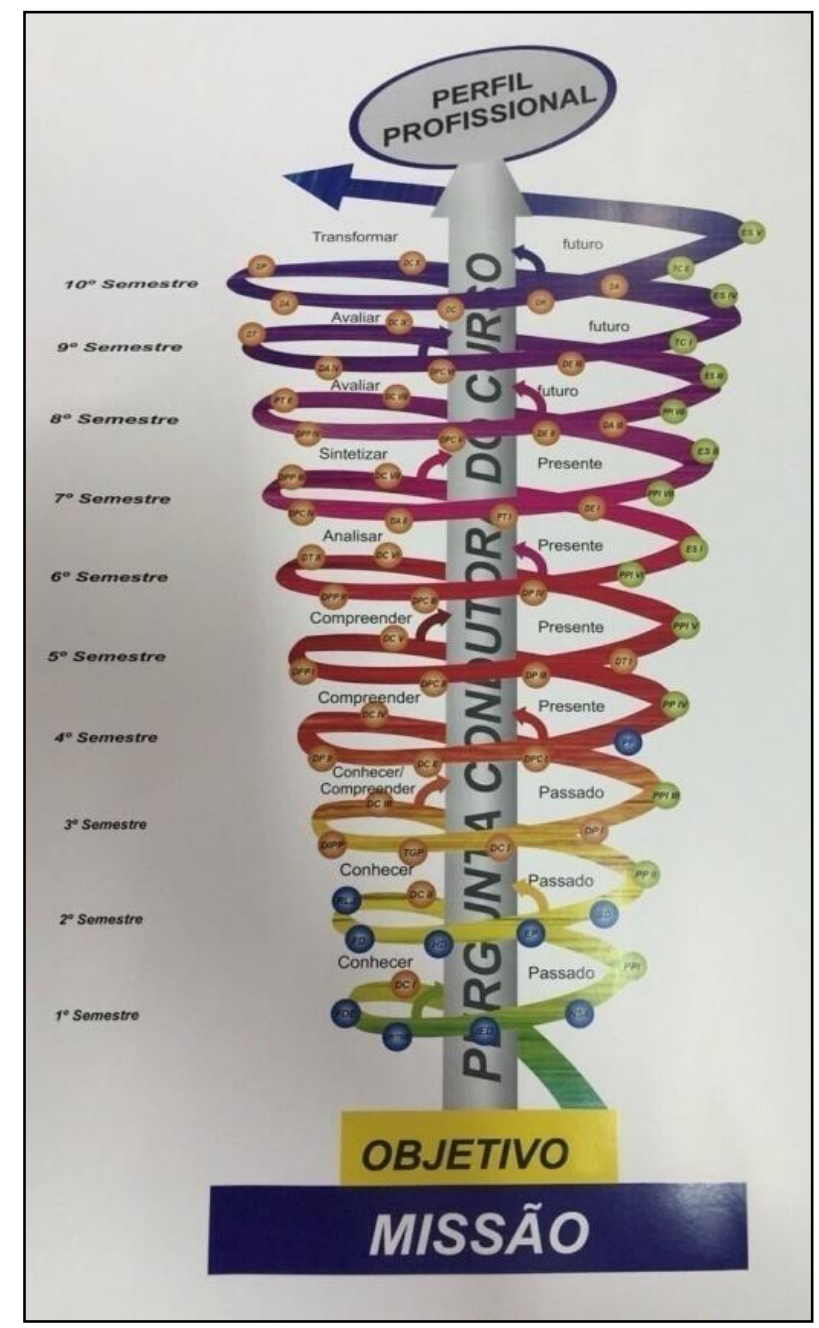

Figura 1. Design curricular do curso

Observando o design, podemos verificar que, do lado direito, encontram-se as modalidades temporais em que o projeto se desenvolve e, do lado esquerdo, a evolução dos objetivos. Acompanhando a linha do conhecimento, aparecem pequenos círculos, que são as disciplinas nas cores de seus eixos.

Assim, demonstramos as inúmeras relações que precisam ser estabelecidas para a construção de um currículo, considerando que a importância da disciplina não se encontra nela mesma, mas nas inúmeras possibilidades que ela pode oferecer ao se religar a outras para a construção do conhecimento. "Porque é preciso ir além do que estamos acostumados a trabalhar em educação, pois sabemos que os conteúdos já não são mais suficientes, embora sejam necessários para a realização de nossa prática pedagógica" (Moraes e Navas, 2010, p. 16).

Compreendidas, então, que as relações são múltiplas, o passo seguinte foi a escolha do procedimento metodológico, focado na formação do profissional, com uma sólida fundamentação teórico-metodológica, mas também com uma prática consolidada, que mantenha um vínculo constante entre teoria/prática, saber/fazer, conhecer/viver, desde o início do curso.

A missão e os objetivos propostos, que definem o perfil e o caminho cíclico a ser percorrido, neste caso são sustentados pelo projeto inter/transdisciplinar. Neste modelo curricular, buscamos interligar a construção do conhecimento de forma horizontal e 
vertical. O centro dessas relações, ou o elemento integrador, é pautado por uma pergunta condutora (eixo que sustenta o design). Essa pergunta é dividida em subperguntas que são os elementos integradores de cada semestre, e que vão sendo respondidas de forma acumulativa, ampliando o conhecimento. Para que as subperguntas sejam respondidas, a matriz curricular conta, a cada semestre, com uma disciplina denominada "Projeto de Pesquisa Interdisciplinar", que funciona como aglutinadora e organizadora do projeto de trabalho do semestre, buscando a efetivação da inter/transdisciplinaridade.

A linha que representa o conhecimento sugere que a aprendizagem ocorre em forma de espiral, um fenômeno crescente e contínuo resultante da aprendizagem e do pensamento recursivo. Esse modelo metodológico propõe uma prática acadêmica não fragmentada e não mecânica, considerando que, atualmente, a interdisciplinaridade tem sido muito debatida no campo da pesquisa e do ensino, mas sua prática ainda encontra barreiras para uma efetiva implantação.

A construção do design curricular tem a finalidade de apresentar uma síntese do projeto do curso, permitindo visualizá-lo como um todo, dando a dimensão de sua verticalidade, que começa na missão e nos objetivos e termina no perfil que se pretende construir.

Para apresentar a relação horizontal, pensamos na construção do conhecimento em cada semestre. Para que a compreensão dessa fase fique mais clara, fizemos um corte transversal no design curricular. Portanto, o design do semestre, apresentado na Figura 2, é um corte da espiral do conhecimento. Mas, o que ele representa? O homem e o mundo, as disciplinas e suas religações (sintetizadas em palavras-chaves e oportunizadas pela disciplina PPI) e a metodologia centrada no autoconhecimento.

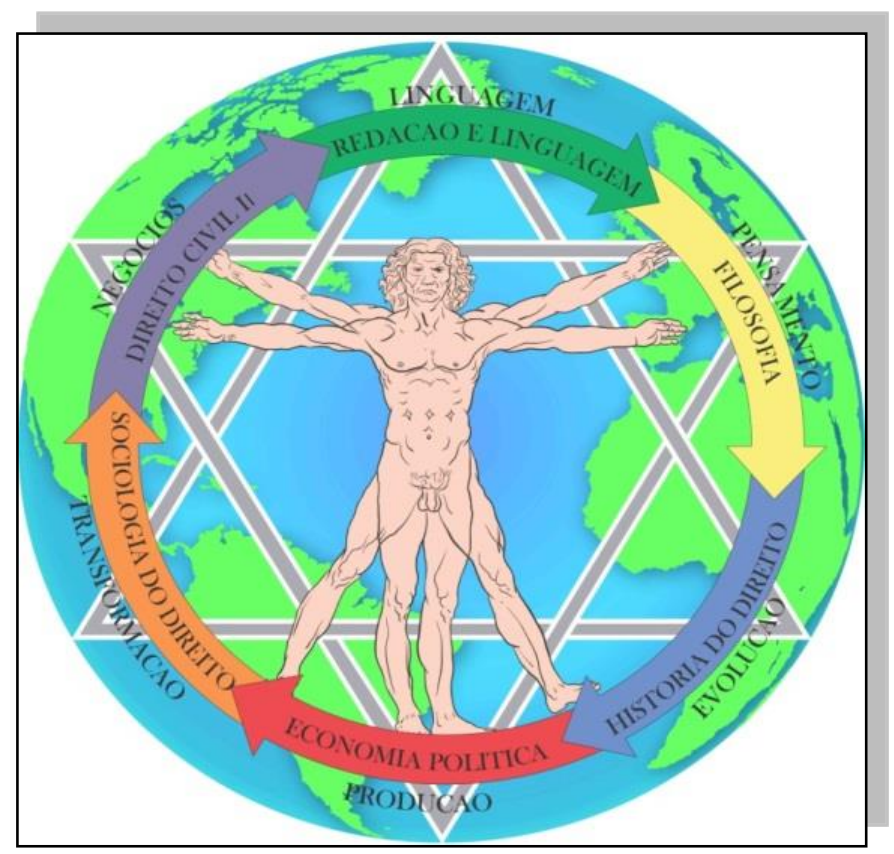

Figura 2. Design do semestre

Cada semestre foi representado por uma imagem circular simbólica, tendo um elemento central, ao redor do qual se congregam as disciplinas. O elemento central dos projetos é a figura humana (utilizamos o homem vitruviano), representativa do ser que adentra no curso, que é o objeto de estudo e das pesquisas de todas as disciplinas, conforme a imagem ilustra. Ao redor do elemento central, o ser humano, giram as 
disciplinas, com uma palavra que representa a sua síntese e que se liga com as demais em um dinâmico movimento de integração, representando a atividade interdisciplinar. Para tanto, existe na matriz curricular uma interdisciplina, denominada Projeto de Pesquisa Interdisciplinar (PPI), que atravessa todo(s) o(s) curso(s).

Na elaboração dessa metodologia, houve preocupação tanto com a particularidade como com a complexidade, tanto com a disciplina como com o currículo, incluindo as relações entre indivíduo, meio e sociedade. Isso acontece porque consideramos que a educação deve priorizar todas as dimensões do ser humano, procurando um equilíbrio interior e exterior. Nesse ponto, percebemos que estávamos utilizando um caminhar pautado pela transdisciplinaridade.

O conhecimento não pertence ao cérebro, mas às relações, às coerências estabelecidas entre o sistema vivo e suas circunstâncias... a aprendizagem surge a partir do acoplamento estrutural do sujeito com o mundo. É um processo que se estabelece no viver/conviver e depende das estruturas internas do sujeito e do que acontece em suas relações com o meio (Moraes, 2010, p. 298).

Como se pode depreender, o design curricular principal foi desdobrado em outros, configurando a totalidade da matriz curricular. Portanto, a articulação não ocorre apenas entre os semestres (verticalidade), mas também entre as disciplinas do mesmo semestre (horizontalidade). Esse movimento integrador, como já foi dito, é direcionado por uma pergunta norteadora de cada curso. Como exemplo, apresentamos a seguir duas perguntas condutoras utilizadas no processo.

Curso de Pedagogia: qual o papel do professor na região de fronteira, frente à multiculturalidade reinante?

Curso de Direito: qual é o papel socioambiental do operador do Direito na região de fronteira frente aos diferentes segmentos do seu campo de atuação?

A procura pelas respostas de tais perguntas condutoras parte sempre do autoconhecimento do acadêmico, evoluindo para a vida desse ser voltada à profissão, à realização, aos grupos sociais, ao ambiente e às relações que se estabelecem, em um movimento recursivo e crescente de aprendizagem, que busca transformações individuais e coletivas.

A partir da construção do currículo, após análise das informações, nossa visão e concepção sobre o curso foi, aos poucos, modificando-se. O exercício de repensar o curso também foi modificando o pensar dos docentes. O grupo de professores compreendeu e visualizou o todo e as partes, percebendo os encaixes das disciplinas. Nesse momento, visualizamos a beleza do quebra-cabeça montado e sua rede de relações. Não tínhamos tal visão anteriormente e, sem ela, a transdisciplinaridade não poderia acontecer, porque não era percebida. $\mathrm{O}$ processo de autoconhecimento era vazio e sem sentido para os alunos, pois ele não tinha relação com as disciplinas que eles estudavam.

Ao iniciarmos o estudo do projeto de trabalho da disciplina Projeto de Pesquisa Interdisciplinar do primeiro semestre, fixamos como tema o autoconhecimento. Além disso, focamos o olhar em cada disciplina do semestre, revendo seus objetivos para que atendessem, em conjunto, ao projeto de trabalho, auxiliando no processo de autoconhecimento.

Refletindo sobre o objetivo das disciplinas, visualizamos que cada uma teria uma palavra-chave, representando sua essência: por exemplo, a disciplina Ciência Política, do curso de Direito, poderia focar-se no sujeito político. Os alunos poderiam visitar a Câmara 
Municipal para verificar como acontecem as sessões, como são planejadas, o que é priorizado, para compreenderem melhor como é possível exercer a cidadania. Neste pensamento surgiu a palavra-chave, "cidadania", e os conteúdos disciplinares voltaramse para a concretização dessa atitude. A disciplina Noções Socioantropológicas poderia focar-se no sujeito que é membro de uma sociedade, com determinadas características, e no sujeito como fruto de uma cultura, que se mescla no espaço social com outras culturas. Poderiam visitar uma aldeia indígena ou o Centro de Tradições Gaúchas para verificarem as características de cada grupo social. Aqui a palavra-chave poderia ser "alteridade". Diferentes palavras-chave foram surgindo e as disciplinas desviaram o foco centrado no conteúdo, passando a ter como centro o ser que aprende e questiona: quem sou nessa sociedade e cultura? Quais são suas marcas presentes em mim? E assim por diante. Assim, com uma reflexão sobre cada disciplina e sobre o currículo como um todo, o curso começou a ganhar vida.

Em comparação ao que estava sendo feito, o processo de autoconhecimento desenvolvido anteriormente parecia vazio e, por esse motivo, os alunos não o compreendiam. Dessa forma, as disciplinas passaram a contribuir mais para o autoconhecimento e para a vida do acadêmico, sendo suas múltiplas relações, assim, melhor esclarecidas.

Com a definição de palavras-chave para cada disciplina, uma teia foi sendo construída a cada semestre e ligando-se aos demais, tendo como fio condutor e integrador desse caminhar a parte da pergunta referente ao semestre. Já a disciplina PPI foi costurando ainda mais os saberes disciplinares e os semestres. Assim, visualizamos o design do curso todo interligado!

Para responder à ampla questão condutora do curso, a cada semestre, os professores se reúnem, observam as palavras integradoras e procuram religar suas disciplinas, por meio de um projeto de trabalho coordenado pela disciplina PPI. Nesse processo de trabalho, a pesquisa vai sendo introduzida desde o primeiro semestre, pois é ela que vai direcionar a busca pela resposta. Dessa maneira, também se conduz o aluno a um amadurecimento, para o desenvolvimento futuro do seu Trabalho de Conclusão de Curso.

Essa forma de trabalhar fica definida no plano de ensino de cada disciplina e, no final do semestre, os acadêmicos apresentam, em forma de seminário, como definiram a resposta e explicam qual foi a contribuição de cada disciplina para sua compreensão. Dessa forma, compreende-se a interdisciplinaridade como a união de pessoas e disciplinas em busca da solução de um problema, construindo conhecimentos. A questão central apresentada surge como uma dúvida que, além de orientar o processo investigativo do curso, pode auxiliar na orientação da própria vida humana, atingindo objetivos transdisciplinares.

Portanto, a interdisciplinaridade e a transdisciplinaridade complementam a abrangência metodológica dessa proposta curricular, conforme apresentado na Figura 3, pois, segundo Nicolescu (2000), ambas as teorias "são flechas do mesmo arco, que é o arco do conhecimento".

Os estudos que estruturaram essa proposta metodológica tiveram como referência a interdisciplinaridade, contida na obra de Fazenda (2008), o pensamento complexo de Morin (2007), os três pilares metodológicos propostos por Nicolescu (2001) (a teoria da complexidade, a lógica do terceiro incluído e os diferentes níveis de realidade) e as três dimensões de formação apontadas por Paul e Pineau (2005) (autoformação, heteroformação e ecoformação). 


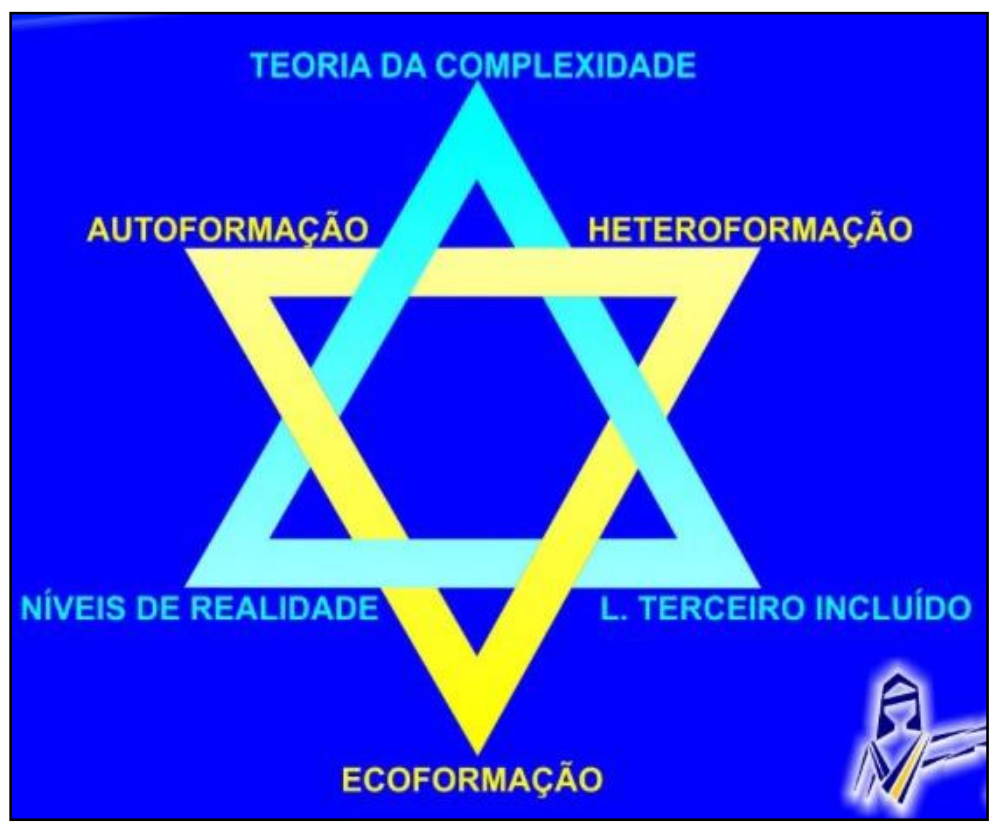

Figura 3. Metodologia do curso

Moraes (2010, p. 298) explica que toda a aprendizagem gera mudanças e transformações estruturais na nossa organização viva e que: "Todo processo de formação pressupõe autoformação, em coexistência com o outro (heteroformação) e com as circunstâncias vividas (ecoformação)". Ainda como propõe Moraes (2010), integrando as dimensões propostas por Nicolescu e por Pineau, surge uma imagem: o hexagrama que apresenta a síntese das abordagens metodológicas e, por esse motivo, encontra-se no centro do design representativo de cada semestre.

\section{Os professores e a capacitação continuada}

As mudanças curriculares que foram sendo pensadas e aplicadas traçaram um caminho que buscou uma participação maior do acadêmico nas questões relativas à vida, refletindo sobre assuntos que ultrapassam os limites das disciplinas. Da mesma forma, o foco do professor também foi deslocado do conteúdo disciplinar para os problemas da vida que afetam o planeta e o próprio acadêmico.

Estamos subindo degraus, pensamos! Saímos do patamar disciplinar para o interdisciplinar, buscando a implantação de um projeto transdisciplinar. Para tanto, começamos a refletir sobre os problemas que ainda estávamos enfrentando em relação à figura do professor. Tínhamos classificado os professores em três tipos: os que queriam cumprir o projeto de curso, mas não sabiam como; os que batalhavam e estudavam para cumpri-lo; e os que continuavam disciplinares e não queriam mudar, mesmo com os programas de capacitação continuada.

Entretanto, ao começarmos a estudar os teóricos da interdisciplinaridade e da transdisciplinaridade para traçarmos as principais mudanças curriculares, começamos a refletir sobre como seria possível modificar as atitudes dos professores, uma vez que temos ciência que um professor só se torna inter ou transdisciplinar quando muda sua atitude frente ao processo de ensino e aprendizagem, na concretização de sua prática docente, e isso acontece progressivamente e de acordo com a evolução de cada um. 
Sabendo também que os professores trazem para a sua prática os modelos da sua própria graduação/formação, que são disciplinares, cada informação classificada dentro de um contexto próprio e limitado.

A pesquisa com o grupo focal demonstrou que a mudança curricular proposta resultou em uma mudança paradigmática, que, segundo Morin (2013, p. 191), reflete um paradoxo: "não se pode reformar a instituição sem antes reformar as mentes, mas não se pode reformar as mentes sem antes reformar as instituições". Nosso trabalho foi feito de modo concomitante, ou seja, remodelávamos o projeto do curso, a matriz com as respectivas disciplinas e, ao mesmo tempo, oferecíamos a capacitação aos professores. Entretanto, não podíamos atropelar e apressar o professor, que precisa de um tempo para refletir sobre a proposta, sobre o curso e sobre suas atitudes. Mas, foi possível constatar que uma nova atitude estava sendo construída junto com as reflexões para a construção do projeto do curso.

Para o começo de cada período letivo, é feita uma capacitação mais intensa que revê as linhas gerais do projeto e aceita sugestões dos professores para implementá-lo, integrando os novos professores. Todos os semestres, o projeto de pesquisa interdisciplinar do curso é planejado e discutido por todos os professores, e cada disciplina oferece sua contribuição para a compreensão da dúvida, ajudando a respondêla. Ao longo do semestre, as capacitações são mensais e o NDE acompanha todo o processo, para que se possa cumprir o projeto, planejando-o, avaliando-o e replanejandoo. Portanto, trata-se de um processo cíclico e contínuo, com a participação dos docentes.

Esses estudos acontecem de duas formas: presenciais e on-line, pelo ambiente moodle. As reuniões on-line preparam para a reunião presencial e têm como base a leitura de teóricos que fundamentam a metodologia do curso. Os professores recebem um texto com perguntas, refletem sobre ele e, na reunião presencial, discutem-no e apresentam suas conclusões para os demais professores, relacionando-o com o projeto de curso e a metodologia aplicada.

O objetivo da capacitação continuada é melhorar o processo de ensino e aprendizagem, para ajudar os acadêmicos na construção de seu conhecimento. Pretendese fazer isso de forma não fragmentada, percebendo a função de cada disciplina na formação e as relações que se estabelecem, utilizando principalmente a pesquisa como condutora do processo.

Com os estudos realizados, os diálogos e as escolhas conjuntas, os professores se sentem partícipes do projeto e ficam motivados para pô-lo em prática. Sabemos que nem todos agem com a mesma motivação, mas temos que compreender que as pessoas não são iguais, por isso devemos respeitar as diferenças e praticar a espera. A proposta tem dado certo, os professores estão confiantes, pois participam da construção do currículo, verificando, por meio das avaliações, o crescimento do curso e do próprio conhecimento.

\section{Considerações finais}

O trabalho inter/transdisciplinar favorece a articulação entre os conteúdos científicos e os conteúdos da vida humana, resultando em um compromisso social da instituição na formação de um egresso que busque a concretização da cidadania, bem como a construção de uma sociedade mais justa, humana, solidária e igualitária. Um currículo construído com base nesses valores deve oferecer ao aluno conhecimentos 
teóricos e práticos, e uma das formas de conectar essas experiências é o Estágio Supervisionado, com as atividades internas e externas. Outra forma de ligação de saberes são as atividades de extensão, que permitem ao acadêmico participar de atividades no seio da comunidade.

Dessa forma, a instituição não precisa aguardar o fim do curso para que os acadêmicos melhorem a qualidade de suas vidas e das dos que estão ao seu redor. Assim, a mudança de atitude e dos compromissos com a cidadania vai sendo fomentada por todas as disciplinas da matriz curricular, com sua aplicabilidade imediata. Isso ocorre porque essa mudança de paradigma aflora nas atividades práticas - por meio da experiência da solidariedade e empatia, movidas pelo espírito crítico e humanista -, sendo potencializada por todas as disciplinas curriculares.

Para que os acadêmicos cheguem a essa compreensão, o curso precisa ser conduzido por uma metodologia inter/transdisciplinar. Logo, aquilo que denominamos partes da matriz curricular, ou disciplinas, na verdade só serão compreendidas se forem enfocadas como elemento de um todo em constante relação. Por esse motivo, não se utiliza a expressão "grade curricular", mas sim "matriz curricular", uma vez que grade remete ao sentido de algo fechado em si mesmo.

Capra (2012, p. 47), ao explicar a visão sistêmica de mundo, oriunda da física quântica, afirma: "Aquilo que denominamos parte é apenas um padrão numa teia inseparável de relações". Portanto, a metodologia adotada para os cursos das Faculdades Magsul se preocupa com a compreensão das relações existentes entre as disciplinas (interdisciplinaridade), que transcendem o campo disciplinar para atingir a melhoria da qualidade de vida no planeta (transdisciplinaridade).

A matriz curricular - formada pelas disciplinas (teórico-práticas), pelo estágio supervisionado, pelas atividades complementares, pelas atividades de ensino, pesquisa e extensão, planejadas em um projeto de curso inter/transdisciplinar - pretende construir um perfil acadêmico almejado e um currículo mais atual, que atenda às necessidades da sociedade contemporânea.

Nossos estudos ainda não findaram, e pensamos que nunca findarão, pois sempre estamos buscando teóricos que estudam a mesma temática para ampliar nossos conhecimentos. A equipe pedagógica dos cursos, por meio do Núcleo Docente Estruturante (NDE), vem estudando práticas metodológicas que atendam à mesma temática dentro das necessidades regionais. Assim, busca-se alcançar uma prática pedagógica mais dinâmica e eficiente, que integre alunos, professores, disciplinas, cursos, possibilitando soluções aos desafios da contemporaneidade.

Se os objetivos planejados estão sendo atingidos, ainda não podemos confirmar, esperamos que sim; e trabalhamos para isso. Mas, já podemos perceber que os cursos das Faculdades Magsul estão mudando sua história com base em estudos e pesquisas que propõem um currículo mais atual, na legislação educacional, na demanda social regional e na melhoria da qualidade de vida. Esperamos que o profissional egresso desses cursos atinja uma formação mais completa, uma vez que aprende a refletir sobre sua própria prática e sobre sua vida, recebe um ensino de qualidade, pautado pela investigação da realidade, e compreende as relações entre sua formação e a vida.

Finalizando, queremos pontuar que estamos, nesse momento, com desejo de melhorar a realidade educacional, de maneira acertada, construindo projetos de cursos mais criativos e inovadores. Nesse processo, com certeza, obstáculos surgirão, como já surgiram, mas a vontade de acertar é tão grande que não vai permitir que o desânimo iniba 
novos estudos, novas reflexões e a constante avaliação do processo de ensino e aprendizagem, na busca incessante pela melhoria do ensinar e do aprender, com objetivos que ultrapassem os muros da faculdade, para a construção de uma vida melhor.

Tudo o que foi narrado já vislumbra uma nova realidade: a alegria de criar algo novo, a coesão de um grupo, o sucesso nas avaliações externas do MEC e do ENADE, além da apresentação dessa proposta em vários congressos, dentro e fora do país. Entretanto, um projeto nunca está pronto, está sempre em construção, buscando sempre sua melhor versão.

Um projeto é um sonho a ser realizado, é um guia, uma forma de caminhar! Mas sabemos que trabalhamos em um mar de incertezas, visando à concretização de um currículo para um curso superior com possibilidades de se transformar em uma educação mais coerente, mais afetiva, mais justa, que possa contribuir para vidas melhores.

\section{Referências}

Brasil. (1998). Constituição da República Federativa do Brasil. Brasília: Senado Federal.

Brasil. (2013). Censo da Educação Superior. Brasília: Instituto Nacional de Estudos e Pesquisas Educacionais.

Capra, F. (2012). A Teia da Vida: uma nova compreensão científica dos sistemas vivos. $13^{a}$ ed. São Paulo: Cultrix.

Faculdades Magsul (2012). Plano de Desenvolvimento Intitucional. Ponta Porã: Faculdades Magsul.

Fazenda, I. (2008). Didática e interdisciplinaridade. 13ª ed. Campinas: Papirus.

Gatti, B. A. (2012). Grupo Focal na pesquisa em Ciências Sociais e Humanas. Brasília: Liber Livro Editora.

Josgrilbert, M. F. V. (2004). O sentido do projeto em educação: uma abordagem interdisciplinar. Tese de doutoramento. São Paulo: PUC/SP.

Lüdke, M. e André, M. E. D. A. (1986). Pesquisa em educação: abordagens qualitativas. São Paulo: EPU.

Moraes, M. C. (2010). Complexidade e currículo: por uma nova reflexão. Polis: Revista de la Universidad Bolivariana, 9(25), 289-311. Recuperado em 12 de jan. de 2019, de https://scielo.conicyt.cl/pdf/polis/v9n25/art17.pdf.

Moraes, M. C. (2008). Pensamento eco-sistêmico: educação, aprendizagem e cidadania no século XXI. $2^{\mathrm{a}}$ ed. Petrópolis: Vozes.

Moraes, M. C. e Navas, J. M. B. (2010). Complexidade e transdisciplinaridade: teoria e prática docente. Rio de Janeiro: Wak Editora.

Moraes, M. C. e Suanno, J. H. (2014). O pensar complexo na educação. Rio de Janeiro: Wak Editora. 
Moreira, A. F. B. e Candou, V. M. (2007). Currículo, conhecimento e cultura. In: A. F. B. Moreira e outros (Org.). Indagações sobre currículo: currículo, conhecimento e cultura (pp. 17-46). Brasília: Ministério da Educação, Secretaria de Educação Básica.

Morin, E. (2013). A Via: para o futuro da humanidade. Rio de janeiro: Bertrand Brasil.

Morin, E. (2007). Introdução ao pensamento complexo. $3^{\mathrm{a}}$ ed. Porto Alegre: Sulina.

Morin, E. (2000). Complexidade e transdisciplinaridade: a reforma da universidade e do ensino fundamental. Natal: EDUFRN.

Nicolescu, B. (2001). O manifesto da transdisciplinaridade. São Paulo: Trion.

Nicolescu, B. (2000). Educação e transdisciplinaridade. Brasília: UNESCO.

Paul, P.; Pineau, G. (Org.). (2005). Transdisciplinarité et formation. Paris: Harmattan.

Suanno, J. H. (2014). A escola que desenvolve seu potencial criativo. In: V. Silva, V. L. S. e Silva e F. Schroeder (Orgs). Novos Talentos - processos educativos em ecoformação (pp. 45-53). Blumenau: Editora Legere.

Torre, S., Pujol, M. A. e Moraes, M. C. (2008). Transdisciplinaridade e Ecoformação: um novo olhar sobre a educação. São Paulo: Triom.

Data do recebimento: $26 / 07 / 2019$

Data da revisão: $17 / 10 / 2019$

Data do aceite: 23/10/2019 